\title{
Residual stress gradients in AISI 9254 steel springs submitted to shot peening and heat treatment for increased fatigue resistance
}

\author{
Larissa Vilela Costa ${ }^{1, a}$, José Rubens Gonçalves Carneiro ${ }^{1, b}$, \\ Rogério Pinto Coelho Catalão ${ }^{2, \mathrm{c}}$, Omar Khayyam Ribas ${ }^{2, \mathrm{~d}}$ and Pedro Brito ${ }^{\star 1, \mathrm{e}}$
}

\author{
${ }^{1}$ Pontifícia Universidade Católica de Minas Gerais, Av. Dom José Gaspar 500, 30535-901 Belo \\ Horizonte MG, Brazil.
}

${ }^{2}$ FIAT Powertrain, Av. Contorno da Fiat, 31000-000 Betim MG, Brazil

alavilela_engmec@yahoo.com.br, bjoserub@pucminas.br, comar.ribas@fiat.com.br, drogerio.catalao@fiat.com.br, epbrito@pucminas.br, eppbrito@gmail.com

\section{* Corresponding author.}

Keywords: Residual stress, X-ray diffraction, multiple shot peening, fatigue, heat treatment.

\begin{abstract}
The presence of surface and subsurface residual stresses in steel components has a significant influence on fatigue resistance. In the present work, surface modification of AISI 9254 steel coil springs by heat treatment and multiple shot-peening procedures was investigated. Samples were characterized in the as-coiled, quenched, quenched and tempered, as well as submitted to single and double shot peening treatments. Depth resolved residual stress profiles were determined by X-ray diffraction combined with electrolytic dissolution of the steel. Fracture analysis was performed subsequent to fatigue tests by scanning electron microscopy. It was possible to show that double shot peening led to an increase in compressive stresses in the immediate sub-surface region, which improved fatigue resistance relative to the other tested conditions.
\end{abstract}

\section{Introduction}

In automotive suspension systems, the springs perform the important tasks of supporting vehicle weight and absorbing kinetic energy transmitted from the track to the automobile in the form of elastic strain. Common materials for automotive suspensions are medium carbon steels containing $\mathrm{Si}, \mathrm{Cr}$ and $\mathrm{Mn}$ additions, which offer elevated ductility, strength and hardenability [1]. Given the nature of their operation, automotive springs require excellent fatigue resistance, which is strongly influenced by material surface conditions since fatigue cracks usually nucleate and grow in surface or sub-surface regions. For this reason, various surface treatments are currently applied in the automotive industry with the objective of improving component life or reducing weight by increase in performance $[2,3]$.

An important surface modification technique widely employed for increasing fatigue properties of automotive components is shot peening. In shot peening the component is bombarded with high velocity shots of a hard material causing plastic deformation at the surface and sub-surface regions. As a consequence, the material undergoes strain-hardening, which increases yield strength at the surface, and the imposition of compressive residual stresses [4] which hinder crack nucleation and growth increasing fatigue resistance, as attested by numerous researchers [5-11]. Furthermore, shot peening is a highly flexible process that can be applied to components with various geometries and also increases resistance to stress corrosion cracking, fretting and erosion [12].

Although the role of shot peening in enhancing fatigue resistance by the generation of compressive residual stresses is well understood, detailed investigations on the relation of process parameters and component performance are less common [13]. For instance, it is still matter of debate whether the major benefits to fatigue performance are due to the compressive residual stress field itself or rather to changes in the microstructure of shot peened components [14]. Recent works directed towards incorporating shot-peening effects in predictive fatigue life models have also highlighted the need for detailed knowledge on the effects of strain hardening, compressive residual stresses, surface roughness (increased by shot peening) and, eventually, phase transformations (e.g. in heat treated steel parts due to the presence of retained austenite) [15-17]. 
The objective of the present work is to investigate the correlation between fatigue life and the near surface stress distribution of automotive springs which were subjected to heat treatment and both single and double shot peening treatments. Double shot peening is interesting because of the possibility of increasing fatigue properties [13]. The springs were made of AISI 9254 steel, a high strength steel commonly used in the automotive industry [7]. Residual stress gradients were determined by X-Ray Diffraction (XRD), one of the choice techniques for this type of analysis [18, 19], and fatigue life was evaluated for different surface conditions. In order to provide insight on the failure mechanism of the springs, fracture analysis was conducted by Scanning Electron Microscopy (SEM).

\section{Experimental Procedure}

Materials. Samples of AISI 9254 steel were initially received in the cold drawn state in the form of $2105 \mathrm{~mm}$ length and $11.45 \mathrm{~mm}$ diameter bars. The chemical composition of the steel bars, as informed by the supplier, is presented in Table. 1.

Table 1. Chemical composition of AISI 9254 steel (all values in wt.\%)

\begin{tabular}{l|l|l|l|l|l|l}
\hline$\% \mathrm{C}: 0.520$ & $\% \mathrm{Mn}: 0.696$ & $\% \mathrm{Si}: 1.268$ & $\% \mathrm{P}: 0.008$ & $\% \mathrm{~S}: 0.006$ & $\% \mathrm{Ni}: 0.159$ & $\% \mathrm{Al}: 0.022$ \\
\hline$\% \mathrm{Cr}: 0.668$ & $\% \mathrm{Cu}: 0.197$ & $\% \mathrm{~V}: 0.003$ & $\% \mathrm{Sn}: 0.003$ & $\% \mathrm{Mo}: 0.001$ & $\% \mathrm{Nb}: 0.001$ & $\% \mathrm{~B}: 0.001$ \\
\hline
\end{tabular}

The first processing stage involved heating to a controlled temperature between 890 and $900{ }^{\circ} \mathrm{C}$ for 15 minutes. Afterwards, the bars were coiled at high temperature in order to obtain a helical format, as illustrated in Fig. 1. Following high temperature coiling, the springs were immediately quenched in oil and subsequently tempered for $45 \mathrm{~min}$ between $350{ }^{\circ} \mathrm{C}$ and $400{ }^{\circ} \mathrm{C}$. The springs were then submitted to a preload process, whereby compression surpassing the materials yield stress was performed. Upon release of the compressive load, the springs were submitted to non-destructive inspection by magnetic particles. Samples containing surface cracks or discontinuities were rejected.

Sample springs from different stages of the production process were selected for further analysis. The selected samples were: As Coiled (AC), Quenched (Q), Quenched and Tempered (QT), quenched and tempered with Single Shot Peening (SSP), quenched and tempered with Dual Shot Peening (DSP).

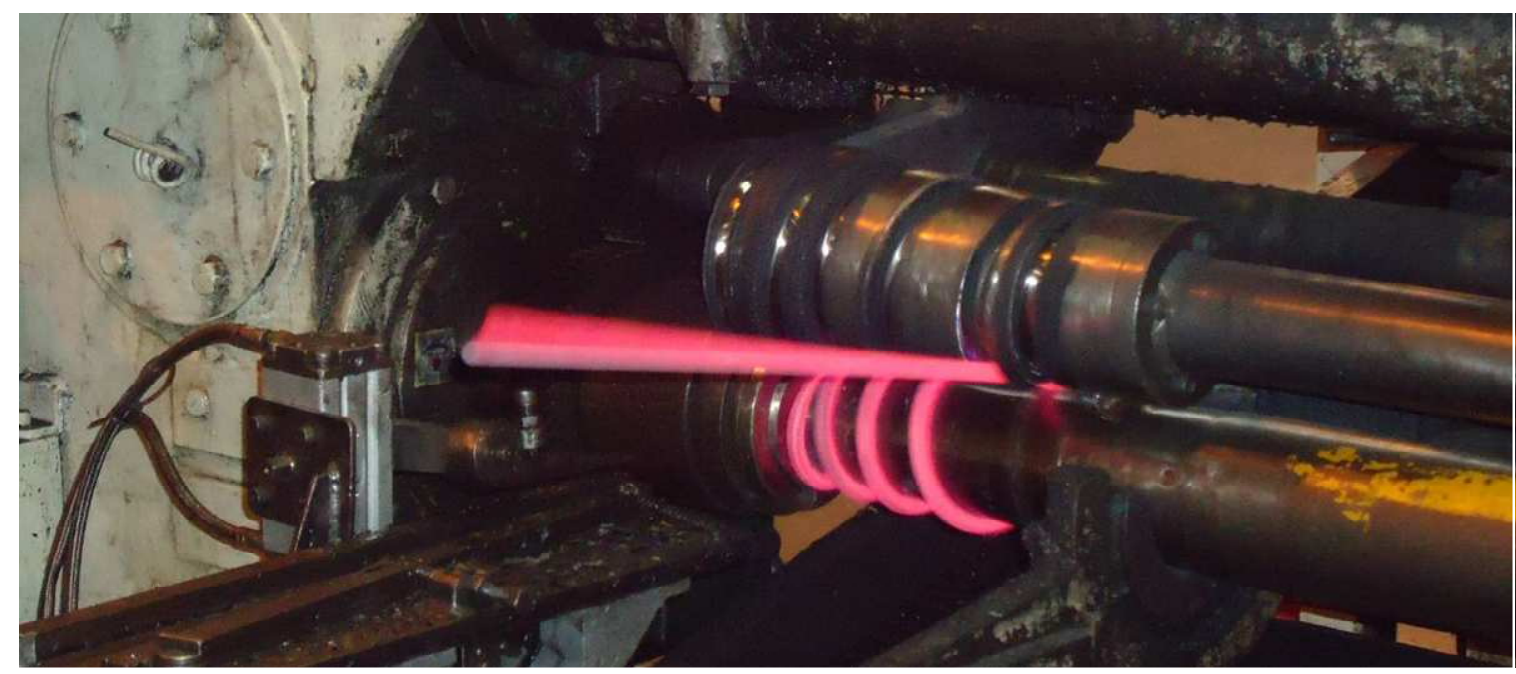

Figure 1: High temperature coiling of the AISI 9254 steel springs.

Shot Peening Treatment. Shot peening was conducted on samples moving over a conveyer belt with controlled speed for a total of $90 \%$ coverage. The shot peening powder was composed of particles with diameters $0.297 \mathrm{~mm}(5 \%), 0.710 \mathrm{~mm}(35 \%), 0.590 \mathrm{~mm}(50 \%)$ and $0.420 \mathrm{~mm}(10 \%)$. The Almen intensity values were $20 \mathrm{~A}$ and $25 \mathrm{~A}$ for the extremities and center of the springs, 
respectively. Because the treatments were conducted in a production line, the DSP samples had to be shot-peened once, removed from the conveyer belt, and then submitted to the procedure once again. This allowed for redistribution/relaxation of the residual stresses and is expected to alter the final residual stress field in the steel springs.

Residual Stress. Residual stress analysis by XRD was conducted on samples from all stages of the manufacturing process: AC, Q, QT, SSP and DSP. The stress state on the surface layers was evaluated using a Phillips X'Prt PW3040 diffractometer operating with $\mathrm{Cu} \mathrm{K}_{\alpha}$ radiation. Calculation of the stress values was performed by measuring the reflection of the (211) ferrite lattice plane and applying the $\sin ^{2} \psi$ method [20] over a total of 10 tilt positions in the $-45^{\circ}$ to $45^{\circ} \psi$ interval. For determination of the residual stress variation with thickness, the springs were treated with an acid solution which removed $0.01,0.03,0.06$ and $0.08 \mathrm{~mm}$ thickness by electrolytic dissolution. With $\mathrm{Cu}$ $\mathrm{K}_{\alpha}$ radiation, the (211) ferrite planes reflect at $2 \theta \sim 82^{\circ}$ yielding a penetration depth of $\sim 10 \mu \mathrm{m}$. Thus, average residual stress profile information depths were 0.01 (surface), 0.02, 0.04, 0.07 and $0.09 \mathrm{~mm}$.

Fatigue Testing. Sample springs in the QT, SSP and DSP conditions were submitted to fatigue testing in compression using an eccentric-shaft press with a maximum load capacity of $20 \mathrm{t}$ and maximum speed of $350 \mathrm{rpm}$. The maximum amplitude during the fatigue tests was set to $129 \mathrm{~mm}$ (total length of the coiled springs was $465 \mathrm{~mm}$ ). A frequency of $6 \mathrm{~Hz}$ was employed in order to avoid resonance in the springs.

\section{Results and Discussion}

Residual Stress Profiles. The depth resolved variation of residual stresses for samples in the AC, Q, QT, SSP and DSP conditions are presented in Fig. 2(a) and 2(b). The results presented in Fig. 2(a) suggest a trend by which the residual stresses present at the surface increase with depth, reaching a peak at $0.02 \mathrm{~mm}$ under the surface, and then proceed to decrease as the distance from the surface increases. The maximum stress values noticed were $-100 \pm 10,330 \pm 20$ and $90 \pm 20 \mathrm{MPa}$ for the AC, Q and QT conditions, respectively, all of which occurred at a $0.02 \mathrm{~mm}$ depth. The elevated tensile stresses present at the surface and sub-surface regions in the Q condition occur because the volumetric expansion caused by the martensitic transformation at the surface outweighs the thermal contraction experienced at the center of the springs during cooling in oil [21]. Subsequent tempering produces stress-relief by the partial transformation of martensite, resulting in lower residual stress values for the QT condition, as shown in Fig. 2 (a).

(a)

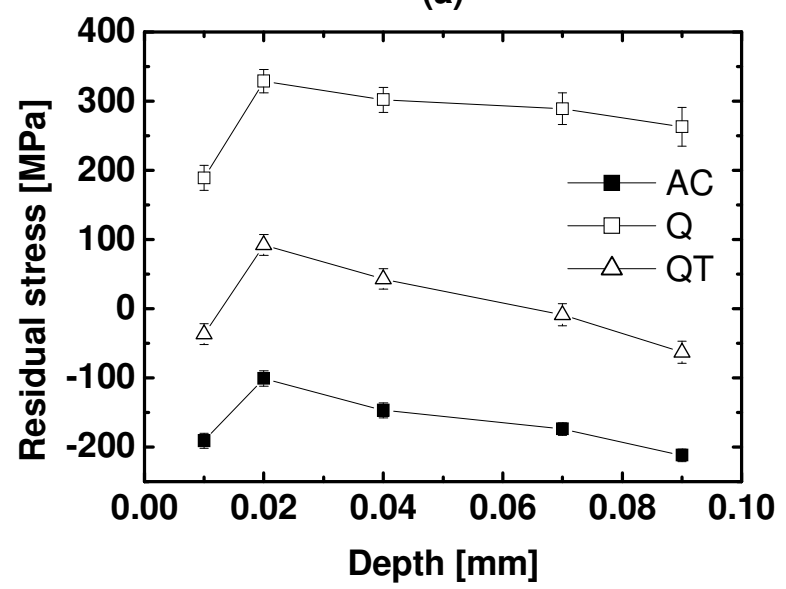

(b)

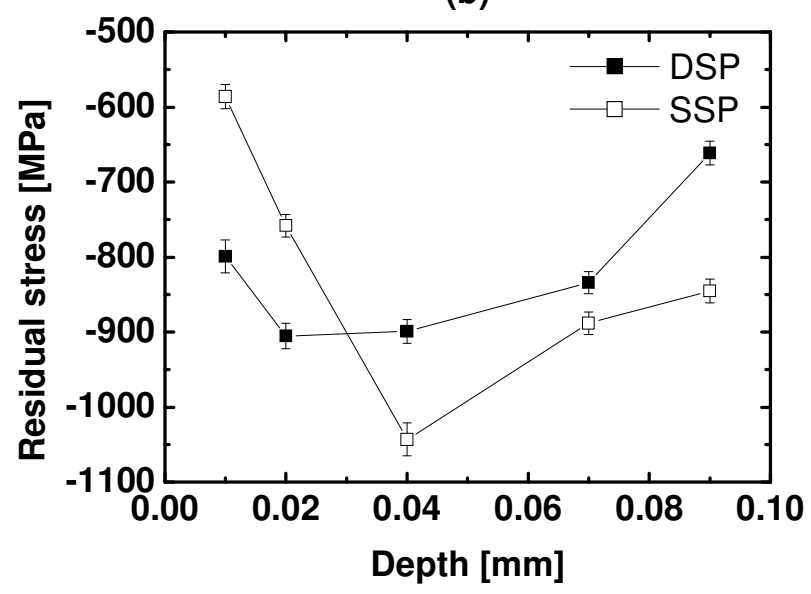

Figure 2: Depth resolved residual stress gradients for samples after various surface modifications: (a) AC, Q, QT conditions and (b) DSP and SSP conditions.

After application of the shot peening process the residual stresses, which were almost negligible in the QT condition, become highly compressive, as presented in Fig. 2(b). The compressive residual stresses occur because of the misfit strain between the plastically deformed surface and elastically deformed sub-surface layers [15]. It is worth noticing that the sample in the SSP 
condition exhibited higher values of compressive residual stress $(-1040 \pm 20 \mathrm{MPa}$ at $0.04 \mathrm{~mm}$ beneath the surface) in comparison to the sample in the DSP condition $(-900 \pm 20 \mathrm{MPa}$ at $0.02 \mathrm{~mm}$ beneath the surface). In turn, the DSP specimen exhibited significantly higher levels of compressive stress in the surface $(0.01 \mathrm{~mm}$ when the X-ray information depth is taken into account) relative to the SSP specimen. The obtained values were $-800 \pm 30 \mathrm{MPa}$ and $-590 \pm 20 \mathrm{MPa}$, respectively, for the DSP and SSP conditions at the surface and $-900 \pm 20 \mathrm{MPa}$ and $-760 \pm 15 \mathrm{MPa}$, respectively, for the DSP and SSP conditions at $0.02 \mathrm{~mm}$ depth. It appears that, by applying a second shot-peening treatment the residual stresses further away from the surface were relaxed whereas those closer to the surface became more compressive. Possible reasons for the stress relaxation in the DSP condition are provided by Scuracchio and co-workers [13] and include: superposition of balancing tensile stresses, localized heating due to intense plastic deformation and relaxation due to cyclic loading, since the springs were shot peened once, load was removed and then shot peened again. Overall, the stress distribution follows the typical pattern obtained after shot peening (see [22] for a recent example).

Fatigue resistance. The fatigue life results, presented in terms of the number of cycles prior to failure, are presented in Figure 3. A clear increase in fatigue performance due to double shot peening can be seen. In principle, the microstructure of the springs in QT, SSP and DSP are all composed by tempered martensite. Therefore, the gain in fatigue life ought to be due to strain hardening and/or compressive residual stresses. The worst performance occurred for samples in the QT condition, which exhibited either tensile or very low levels of compressive residual stress (Fig. 2).

By analyzing the results presented in Fig. 2 and Fig. 3, it seems clear that, in the present case, fatigue life cannot be directly connected to the maximum value of compressive stress present in the specimen. Instead, it appears that only near surface compressive stresses, up to $0.02 \mathrm{~mm}$ in depth, are effective in increasing fatigue life. This is in agreement with a recent study, which showed that fatigue life is also strongly affected by compressive residual stresses located within a $0.02 \mathrm{~mm}$ depth [13]. The behavior is shown more clearly in Fig. 4, where fatigue life is plotted with respect to the residual stress values determined at the surface and at $0.02 \mathrm{~mm}$ depth for the QT (corresponding to 84,700 cycles), SSP $(321,200$ cycles) and DSP (792,000 cycles).

Fracture Analysis. The fracture surfaces of the QT samples, after fatigue testing, are presented in Fig. 5(a) (overview) and Fig. 5(b) (detail). The region of fatigue crack initiation is signaled by arrows in Fig. 5. As expected, failure starts near the surface, which is probably why the DSP specimen exhibited superior fatigue resistance in comparison to the SSP sample, in spite of a lower maximum compressive stress value. The overall fracture

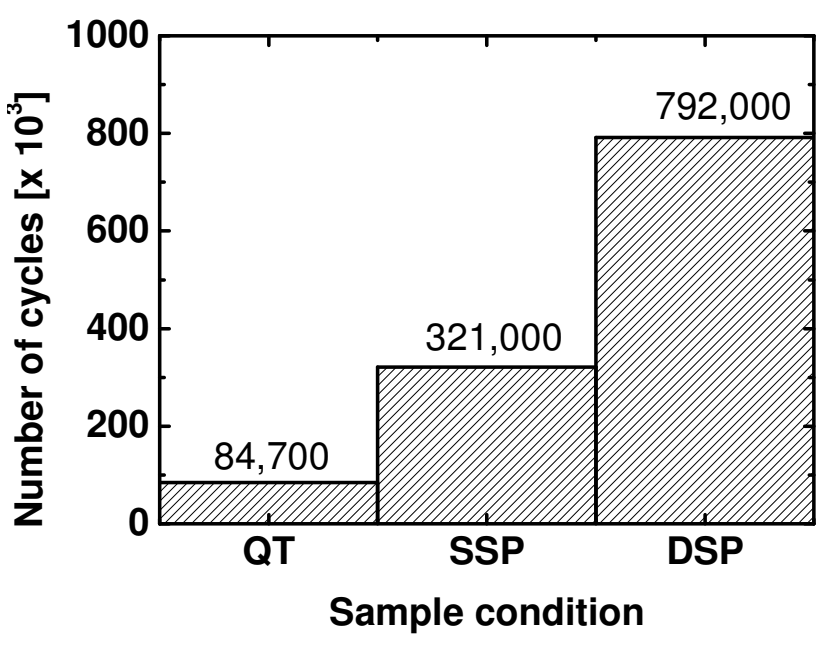

Figure 3: Fatigue life as a function of sample surface condition: QT, SSP and DSP.

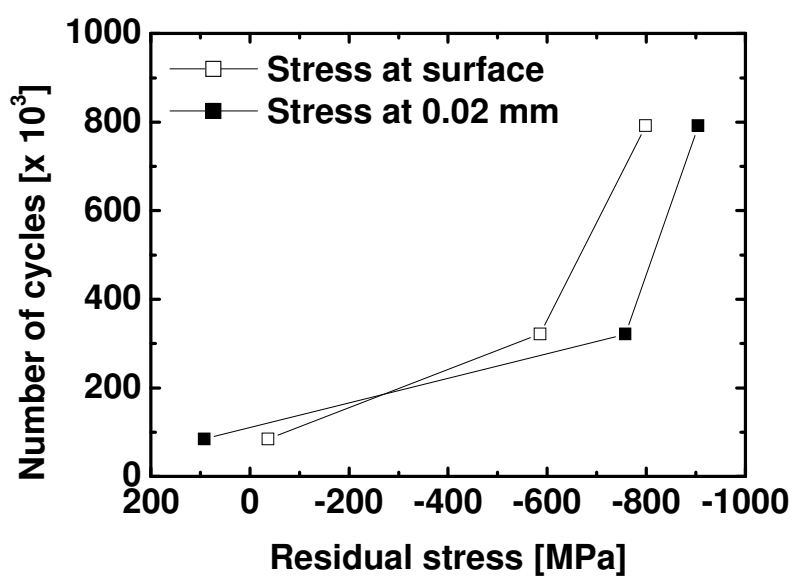

Figure 4: Positive correlation between fatigue life and surface/subsurface compressive residual stress. 
surface presented in Fig. 5(a) discloses different features including intergranular fracture and fatigue grooves. In Fig. 5(b) it is possible to observe the presence of micro cracks, fatigue grooves regions and dimples, indicating points of ductile fracture.
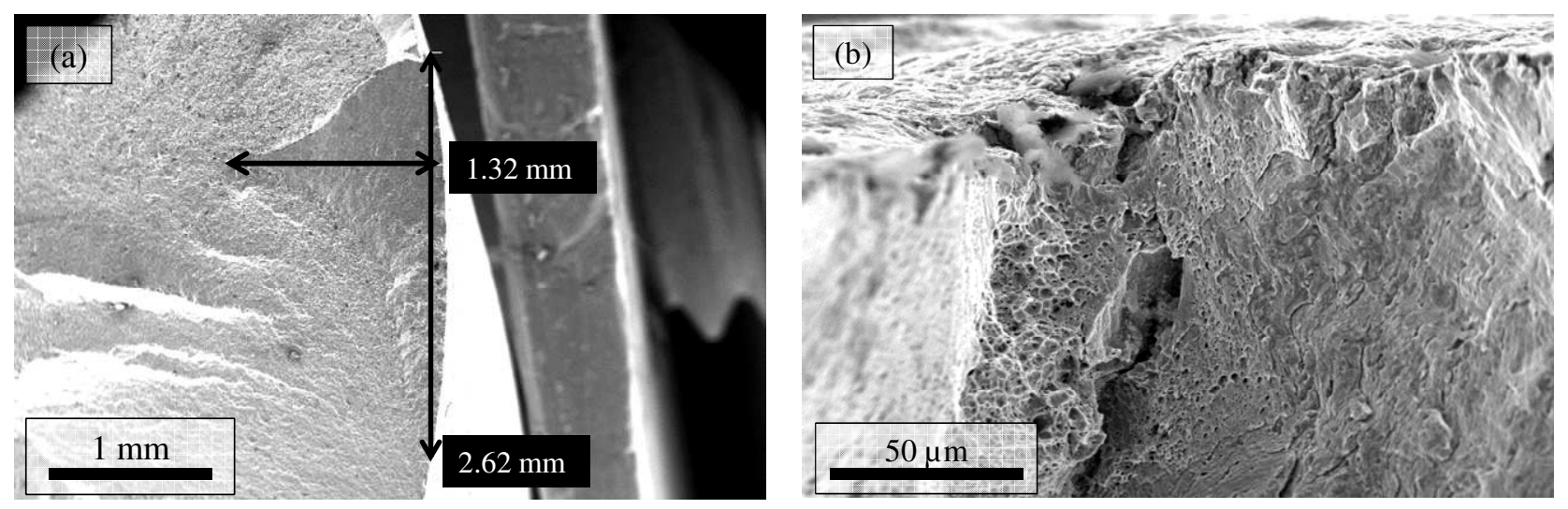

Figure 5: Fracture surface of the QT specimen after fatigue testing: (a) overview showing the crack initiation region and (b) detailed view of the crack initiation region.

\section{Conclusions}

Residual stress profiles and fatigue life of AISI 9254 steel springs were determined by X-ray diffraction and were correlated with fatigue life results. After quenching, the springs exhibited elevated tensile stresses which were relaxed upon tempering. Both single and double shot peening processes introduced compressive residual stresses in the quenched and tempered materials, which led to an increase in fatigue life. It was found that double shot peening increased the fatigue life of the springs to a greater extent in comparison to single shot peening thanks to the generation of higher levels of compressive residual stresses at the surface and at $0.02 \mathrm{~mm}$ from the surface, which is where fatigue damage was found to initiate in the present case.

\section{References}

[1] A. Ardehali Barani, D. Ponge, D. Raabe, Refinement of grain boundary carbides in a Si-Cr spring steel by thermomechanical treatment, Mat. Sci. Eng. A 241 (2006) 194-201.

[2] C. S. Lee, K. A. Lee, D. M. Li, S. J. Yoo, W. J. Nam, Microstructural influence on fatigue properties of a high-strength spring steel, Mat. Sci. Eng. A 241 (1998) 30-37.

[3] Y. Prawoto, M. Ikeda, S. K. Manville, A. Nishikawa, Design and failure modes of automotive suspension springs, Eng. Fail. Anal. 15 (2008) 1155-1174.

[4] M. Kobayashi, T. Matsui, Y. Murakami, Mechanism of creation of compressive residual stress by shot peening, Int. J. Fatigue. 20 (1998) 351-357.

[5] D. M. Li, K. W. Kim, C. S. Lee, Low cycle fatigue data evaluation for a high strength spring steel, Int. J. Fatigue 19 (1997) 607-612.

[6] J. -C. Shin, S. Lee, J. H. Ryu, Correlation of microstructure and fatigue properties of two highstrength spring steels, Int. J. Fatigue 21 (1999) 571-579.

[7] S. Teleki, Enhancement of fatigue life of SAE 9245 steel by shot peening, Mater. Lett. 57 (2002) 604-608.

[8] M. A. S. Torres, H. J. C. Voorwald, An evaluation of shot peening, residual stress and stress relaxation on the fatigue life of AISI 4340 steel, Int. J. Fatigue 24 (2002) 877-886. 
[9] K. K. Liu, M. R. Hill, The effects of laser peening and shot peening on fretting fatigue in Ti6Al-4V coupons, Tribol. Int. 42 (2009) 1250-1262.

[10] S. Bagherifard, M. Guagliano, Fatigue behavior of a low-alloy steel with nanostructured surface obtained by severe shot peening, Eng. Fract. Mech. 81 (2012) 56-68.

[11] Y. Hu, Y. Wu, G. Wang, J. Guo, Surface yield strength gradient versus residual stress relaxation of 7075 aluminum alloy, Adv. Mater. Res. 160-162 (2011) 241-246.

[12] S. Bagheri, M. Guagliano, Review of shot peening processes to obtain nanocrystalline surfaces in metal alloys, Surface Eng. 25 (2009) 3-14.

[13]B. G. Scuracchio, N. B. de Lima, C. G. Schön, Role of residual stresses induced by double peening on fatigue durability, Mater. Design 47 (2013) 672-676.

[14] M. N. James, D. J. Hughes, Z. Chen, H. Lombard, D. G. Hattingh, D. Asquith, J. R. Yates, P. J. Webster, Residual stress and fatigue performance, Eng. Fail. Anal. 14 (2007) 384-395.

[15] K. A. Soady, B. G. Mellor, G. D. West, G. Harrison, A. Morris, P. A S. Reed, Evaluating surface deformation and near surface strain hardening resulting from shot peening a tempered martensitic steel and application to low cycle fatigue, Int. J. Fatigue 54 (2013) 106-117.

[16]K. A. Soady, Life assessment methodologies incorporating shot peening process effects: mechanistic consideration of residual stresses and strain hardening Part 1 - effect of shot peening on fatigue resistance, Mater. Sci. Tech 29 (2013) 637-651.

[17]K. A. Soady, Life assessment methodologies incorporating shot peening process effects: mechanistic consideration of residual stresses and strain hardening Part 2 - approaches to fatigue lifing after shot peening, Mater. Sci. Tech 29 (2013) 652-663.

[18]G. A. Webster. Residual stress distributions and their influence on fatigue lifetimes, Int. J. Fatigue 23 (2001) S375-S383.

[19] R. Menig, L. Pintschovius, V. Schulze, O. Vöhringer, Depth profiles of macro residual stresses in thin shot peened steel plates determined by X-ray and neutron diffraction, Scripta Mater 45 (2001) 977-983.

[20]E. Macherauch, P. Müller, Das $\sin ^{2} \psi$-Verfahren der röntgenoraphischen Spannungsmessung, Z. Angew. Physik, 13 (1961) 305-312.

[21]R. E. Reed-Hill, Physical Metallurgy Principles, second ed., Brooks/Cole Engineering Division, Monterey, 1973.

[22]P. Fu, K. Zhan, C. Jiang, Micro-structure and surface properties of 18CrNiMo7-6 steel after multistep shot peening, Mater. Design 51 (2013) 309-314. 